Ada BELEUȚă

Faculty of Letters, Babeș-Bolyai University

Cluj-Napoca, Romania

beleutaandreea@yahoo.com

\title{
EMPATHET(H)ICS: INTERSUBJECTIVITY, INTEROBJECTIVITY, AND (NON)HUMAN STORYTELLERS IN COLUM MCCANN'S LET THE GREAT WORLD SPIN
}

Recommended Citation: Beleuță, Ada. "Empathet(H)Ics: Intersubjectivity, Interobjectivity, and (Non)Human Storytellers in Colum Mccann's Let The Great World Spin." Metacritic Journal for Comparative Studies and Theory 7.1 (2021):

https://doi.org/10.24193/mjcst.2021.11.13

\begin{abstract}
Tracing some of the inflection points in our conceptualization of empathy, social cognition, intersubjective understanding, and social theories over time, this essay attempts to contextualize and give a possible explanation to the more radical changes determined by the so-called nonhuman turn. Drawing on the theories proposed by Steven Connor, Bill Brown, and Bruno Latour on the relations between human and nonhuman agents, the paper will argue for the inherent potential of things to both exceed the limits of human agency and cognitive capacities (specifically, memory and intersubjective understanding) and foster their expansion. A reading of Colum McCann's Let the Great World Spin (2009) will emphasize the importance of interobjectivity as a mechanism of augmenting empathy and intersubjective understanding. The polyphony of narrativized memories of loss, mourning, trauma and even pre-trauma, in their construction of an alternative history to the 9/11 terrorist attacks, uses things to encode, store, and retrieve memories, as well as to facilitate (re)connections with others beyond boundaries of space, time, or death. Thus, the democratic force of storytelling returns to corroborate "a democracy extended to things" (Latour).
\end{abstract}

Keywords: Irish-American fiction; the nonhuman turn; agency of objects; intersubjective/interobjective understanding. 
"On or about September 11, 2001, human character did not change" (Cohen 3). Or maybe it did, coalescing with the "multiplicity of revolutions that together are radically reshaping the context of our thinking about what it means to be a human being" (Groes 1). Further exploring this question, this essay will start with the assumption that humanity often "proceeded as if human nature had changed" (Pinker 409). On an ethical level - especially after being faced with violent and deliberate acts of inhumanity -, we feel the need to recalibrate our moral compasses, to study the human mind from new perspectives, and to understand its socio-cognitive processes and mechanisms of empathy. A "secondary metacognitive ${ }^{1}$ " level is therefore implicit. In our efforts to readapt our sense-making frameworks to the changing demands of the $21^{\text {st }}$ century, we are witnessing how our brains and our thinking about what it means to be thinking change as well.

In an attempt to identify such changes in the conceptualization, as well as the functioning of human cognition, empathy, and ethical systems of the recent past, my research brings together several strands of the nonhuman turn that can shed light on the extents to which human agency and human cognition - in particular, memory and intersubjective understanding - can be both exceeded and extended through relations with objects. In this sense, it will begin by retracing the gradual shifts in our understanding of empathy as it emerges from the use of metaphors such as putting oneself in another's shoes, in order to eventually reinforce the commonality between human and nonhuman others by justifying their value as objects of compassion. Still "from the side of the subject" (Connor 4), I will then rely on Bill Brown's and Steven Connor's rethinking of the relation between subjects and objects and between things and cognition, respectively, in order to underline how an ontological flattening is not a compulsory part of an ethically responsible approach to the nonhuman. Building on previous links between definitions of empathy and underlying perceptions on the social, it will also turn to Bruno Latour's actor-network-theory. Finally, I will read Colum McCann's Let the Great World Spin (2009) in the light of these theoretical approaches, and argue that it is an accurate representation for how a conscious delving

${ }^{1}$ Roughly, thinking-about-thinking, cognitive scientists define metacognition through metacognitive knowledge - "information that individuals possess about their own cognition or cognition in general" (Moses and Baird 533), and metacognitive regulation -"a variety of executive functions such as planning, resource allocation, monitoring, checking, and error detection and correction" (Brown et al. qtd. in Moses and Baird 534). 
into the democratic power of storytelling expands into "a democracy extended to things" (Latour, Modern 12).

\section{Putting oneself in another's shoes}

In order to refer to and make sense of empathetic and ethical behaviour, one often uses stereotypical phrases such as putting oneself in another's shoes or reading another's mind. However, the actions which are subsequently associated to them become particularly significant in observing gradual shifts in theories on the human mind, social cognition, and intersubjectivity, as well as in the internalized social models. As follows, this section outlines some nodal points that might have been conducive to the nonhuman turn of the humanities.

To begin with, approaches from cognitive sciences argue for an intrinsic social nature of the human mind. In its evolution, it seems that the brain developed a specialized module of social cognition. Endowing humans with folk psychological aptitudes, the theory of mind module reads and interprets the other's behavioural cues in terms of underlying mental states, intentions, or reasons for actions. It allows us to understand, respond and act in relation with other (similar) minds (Herman 12-15). Then, post-Cartesian and postcognitivist theories on the mind - proposing concepts such as enactivism, ${ }^{2}$ the extended mind, embodied or distributed cognition, 3 argue that "minds are inextricably embedded in contexts for action and interaction, and arise from the interplay between intelligent agents and the broader social and material environments that they must negotiate" (9). As far as intersubjectivity and mindreading are concerned, the interdependence and co-constitution of minds and social contexts allowed for invalidating the interpretation of literary characters as exceptional - mentally accessible and easily readable, in comparison to human others. Instead, it is argued that

minds of all sorts [fictional or real] can be more or less directly encountered or experienced - depending on the circumstances. (...) fictional narratives do not provide wholly direct or immediate views of others' minds, and (...) experiencing someone else's I-originarity is not limited to the domain of fiction (9).

\footnotetext{
2 The definition of enactivism proposed by Varela, Thompson, and Rosch may be particularly telling "cognition is not the representation of a pregiven world by a pregiven mind but is rather the enactment of a world and a mind on the basis of a history of the variety of actions that a being in the world performs" (qtd. in Herman 256).

3 For a selection of bibliographical resources on these concepts, see Herman 256.
} 
Partly consonant with Bruno Latour's "sociology of associations" (Reassembling 9), the social becomes the enactment of processes of (inter)action and it extends to embed other - still human, but fictional - agents. In response, theories on the nature and functioning of the human mind are readjusted. The previous understandings of folk psychology through the various models of the theory of mind approach are revised. By taking into consideration the cognitive importance of narrative, intersubjectivity is remodelled on concepts such as narrative competence and folk psychological narratives (Gallagher; Hutto)4. As a result, the recognition of an imaginative and interpretative character of social-cognition enriches the mind-reading trope with an increased degree of responsibility, previously absent from the unconscious employment of a theory of mind.

Owing to the narrative turn, cognitive theories of enactivism find their counterparts in reconfigurations of ethics, empathy, and the social as possessing a narrative dimension of their own. In this sense, there are two concepts that explicitly make use of the putting oneself in another's shoes trope. However, its shortcomings become clear and complementary concepts have to be put forward. The first one is Martha Nussbaum's definition of narrative imagination as "the ability to think what it might be like to be in the shoes of a person different from oneself, to be an intelligent reader of that person's story, and to understand the emotions and wishes and desires that someone so placed might have" (qtd. in Meretoja 3). Intersubjective understanding is no longer merely an inquiry into the other's intentions and reasons for action - hence a theory of mind type of mind-reading, but also an effortful and intelligent interpretation of his/her unintentional mental states. The shift is further noticeable in Hanna Meretoja's construction of hermeneutic narrative ethics. Drawing on the Heideggerian tradition of interpretation as the human mode of being in the world (4-5), she argues that we are "always and already embedded in webs of narratives" (Meretoja 2). Consequently, "the dichotomy between living and telling” (8) is rejected in favour of an interpretative continuum (56) that necessarily embeds all narrating agents. In this way, the responsibility falls on the interpreting subject. The

\footnotetext{
4A narrativized model of the theory of mind, folk psychological narratives "[challenge] the all-toocommon assumption that the primary function of folk psychology is to enable us to carry off thirdperson predictions of the behaviors of others by adopting a speculative stance," in order to argue that "when making sense of [the actions of others], what we are seeking is a narrative that fills in or fleshes out the relevant details of that person's story. (...) Folk psychology is, by my lights, in essence, a distinctive kind of narrative practice" (Hutto xi).
} 
cognitive-hermeneutical narratives of intersubjective understanding that one constructs must remain open and dialogical - "perspective-taking should be understood not merely in terms of putting oneself in the other's shoes, but as a process of entering into a dialogic relation with another mode of experience without letting go of one's own values and beliefs." (302; emphasis added) Gaining a material dimension outside the mental realm, socio-cognitive processes acquire the capacity to affect the embedding social context - and thus an ethical potential.

Because the human mind is no longer understood as interior, inaccessible, or immaterial, it becomes necessary to explore the extents to which mentality can be extended beyond human agents (Shaviro 21). Presumably, human-to-human interaction is possible only after the confirmation that the other has a similar mind and a similar (linguistic) understanding of the embedding social world. Deriving from our rational and linguistic tools as "the guarantors of our commonality" (21), it is an assumption that such cognitive capacities are essential to intersubjective understanding as well. However, exploring the "Consequences of Panpsychism,"5 Steven Shaviro argues that humans' commonality of sapience can be surpassed by the (non)humans' commonality of sentience. Weighing the effects of reconsidering the mental as material and universal on the human/nonhuman divide and on our understanding of empathy, he argues that human-to-nonhuman interaction should not be based on a forced moulding of the other into human forms of rational or linguistic thought, but rather on the acceptance of an equally justifiable and (in)accessible inner experience -

a bat's sonocentric experience - or for that matter, a dog's olfactocentric one - is so different from the oculocentric experience of human beings that we will never be able to literally feel, or entirely understand, «what it is like» to be a bat or a dog (25).

In fact, Shaviro's conclusion is that sentience may precede the mental and the conscious, being the fundamental animating force - "life is possible because there is already sentience, rather than the reverse" (41). It becomes the overarching, radically

\footnotetext{
5 The definition of panpsychism - "in opposition to idealism, Cartesian dualism, and eliminativist physicalism alike," "maintains that thought is neither merely epiphenomenal nor something that exists in a separate realm from the material world. Rather, mind is a fundamental property of matter itself. This means that thinking happens everywhere; it extends all the way down (and also all the way up). There are differences of degree in the ways that entities think, but no fundamental differences of kind" (Shaviro 19-20).
} 
democratizing, commonality of all entities, transcending the "likeness-in-humanterms" (25) that we conditioned our empathetic understanding on. Always juxtaposing examples of animate entities with inanimate ones (for example, a rock or a neutrino), Shaviro equally argues for the latter's capacities to interact, relate, affect, and be affected $(38 ; 40)$. In this way, we learn to recognize that "they have their own reality and their own subjectivity" (25) and begin to make efforts in adapting our human means of understanding, relating, and belonging to their idiosyncratic experience of the world - "because I nevertheless do acknowledge and respect the inner lives and values of other human beings, I can potentially do the same with other entities of all sorts. What's needed, perhaps, is an extension of sympathy" (40; emphasis added).

Without an explicit concern for the nonhuman, Meretoja also suggests that dialogicality, perspective-taking, and perspective-sensitivity are to be extended beyond human subjects - "for a dialogue to take place, the participants must be able to imagine the world of the other as a world that - although different from one's own - is nevertheless a human world (or, in the case of non-human others, a world of experience and suffering)" (304). As for Shaviro, it is not only "a sense of shared humanity," but also "a shared sentiency (...) bind[ing] us together across differences and [fostering] a sense of mutual responsibility that makes possible a shared future for humans and other sentient beings on this shared planet” (Meretoja 125).

\section{An extension of sympathy: interobjective understanding}

Accepting a shared sentience with nonhuman others is only the first step towards completing a nonhuman turn. Starting from "decentering the human in favour of a turn toward and concern for the nonhuman, understood variously in terms of animals, affectivity, bodies, organic and geophysical systems, materiality, or technologies" (Grusin vii), recent approaches from both the humanities and social sciences make explicit efforts towards destabilizing - and, eventually, erasing, the naturalized boundaries of anthropocentrism that perpetuate subject-object binaries. Raising both ontological and epistemological challenges, they ask for a reconsideration of our (self)positioning in a world of human and nonhuman others. This section of the paper will argue that such perspectives get enmeshed as both causes and effects in the "changing demands, and demanding changes" (Groes 2) of the $21^{\text {st }}$ century. While they are deconstructing our naturalized anthropocentric foundations and expanding on our notions of empathy, they are - at the same time, destabilizing our inherited memories 
of what it means to be human. Put under close scrutiny and revision, one of the most disconcerting aspects that arise concerns the extents to which human agency is also reduced. For instance, it is often emphasized that a foreseeable climate disaster can identify the human species with "climatological or geological forces on the planet that operate just as nonhumans would, independent of human will, belief, or desire" (Grusin vii; emphasis added). Nevertheless, it is from this point - despite a probably still restricted, "likeness-in-human-terms" perspective (Shaviro 25), that we learn to consciously recognize the agency in others, human or nonhuman, and to practice the required "extension of sympathy" (40).

Initially, it is important to notice that acknowledging the importance and the potential agency of nonhuman others does not necessarily imply the erasure of ontological differences between subjects and objects. In fact, Steven Connor interestingly notices that intentions of this kind account for perpetuating an implicit incongruity between subjects and objects - "this assumption of an ontological sundering between things and beings often leads to the further assumption that there is therefore also a fundamental antagonism between them" (6). Instead, he argues that the co-dependency between humans and nonhumans is an effect of the ontological difference in the first place -

it is precisely because of the ontological divide between things and beings that the former are so indispensable to the latter, and perhaps vice versa. We become subjects only in our dealings with objects; we need objects precisely because they are not beings. Things are not our antagonists, but nor are they our secret sharers, or coconspirators; rather, they are what I just now called our necessary accessories (6-7; emphasis added).

Denouncing the "covert anthropomorphism" (3) of most ontologies of the object, ${ }^{6}$ Connor maintains that it is not only impossible, but also inefficient to attempt an understanding of things outside or beyond our relations with them. Even more, it is in this relation that their agentic power should and can be recognized. Consequently, refusing to consciously decentre the subject, he starts instead from its side (4). Also, he renounces the commonly shared intentions of blurring ontological divides between ${ }^{6}$ It is also important to notice, along Bruno Latour, that the linguistic differentiation between humans
and nonhumans preserves an "anthropocentric bias" (Reassembling 72 ) as well. 
human and nonhuman entities - "many forms of the new thingly disposition see things not as a refuge or remission of the human at all, but rather as intimately involved with and expressive of it" (5).

Also "[leaving] the subject-object binary in place (while repeatedly discovering it disoriented or displaced)" (Other Things 20), Bill Brown constructs a theory of thingness that puts into perspective the limits of human-to-objects relations. Echoing Shaviro and Meretoja, he conceptualizes thingness as a pre-rational category of sentience and sensations, which - firstly, represents the generative stuff from which subjects and objects co-emerge - "some under-organized material field or some unorganized amalgam or mass: a field of sensations before they are organized into discrete objects" (22; emphasis added). Secondly, it is constituted into the commonality that allows for other inter(re)connections and possibilities of mutual other-and self-understanding. In this case, thingness refers to an intrinsic potentiality for "interobjective relation[s]" (22) that is latent in all objects and subjects. It is also important to notice that, when produced in their subject-object relation, the two parts are no longer naturally associated with human or nonhuman entities. Instead, the positions are interchangeable - "an object can appear in the subject position" (22), as well as facilitate (or interfere in) other interrelation beyond its own.7

This extension of intersubjective to interobjective understanding renders things - as the signature of "subject-object relation" (22), as cognitively essential. On the one hand, it becomes apparent that objects are encountered through the same socio-cognitive processes as human others. Our relation with them is, as in the case of interpersonal relations, a means of self-knowledge and self-understanding which does not escape the frustrations of partiality - "as they circulate through our lives, we look through objects (to see what they disclose about history, society, nature, or culture above all, what they disclose about us), but we only catch a glimpse of things" (Thing Theory 4). In this sense, the conceptual difference between objects and things becomes essential, emphasizing our impossibility to completely integrate things rationally. On the other hand, there is an opposing force which enables things to elicit our defamiliarized (and defamiliarizing) perception and interpretation. Either in chance

7Even though the concept of interobjectivity can refer to human-to-human relations as well, this paper will continue to refer to them as intersubjective, in order to avoid confusion and to preserve the nuances of intersubjective understanding as the socio-cognitive mechanism of empathy. 
encounters, when "you cut your finger on a sheet of paper, you trip over some toy, you get bopped on the head by a falling nut" (3-4), or when they malfunction,

when they stop working for us: when the drill breaks, when the car stalls, when the windows get filthy, when their flow within the circuits of production and distribution, consumption and exhibition, has been arrested, however momentarily (4)

objects claim their agentic power and "[assert] themselves as things" (4), asking to be compassionately approached as others.

Returning to Steven Connor's "Thinking Things," it is possible to observe how the reevaluation of human-to-objects relations further determines compensatory reevaluations of our cognitive and meta-cognitive processes. Arguing for a "paradoxical kind of animism" (3), Connor proposes that the resemblance - and thus, the ability to relate, between beings and objects does not stand in the latter's potentially human-like characteristics, but rather in their eluding interobjective understanding similarly (well) to human others -

the object resembles the subject not in sharing its particular powers or capacities, but in exhibiting the power of resistance or reserve, the power to withdraw or withhold itself from being known, that the subject secretly, stubbornly, assumes as its own alone (3).

To him, things acquire a two-fold cognitive involvement. On the one hand, due to their capacity to "draw, drain and detain our thinking" (4), they become important elements in the development and functioning of social cognition. Either reasserting their "solidarity in alterity" (2) or - contrarily, allowing for humans' extensive mental projections - such as the inkblots of the Rorschach test, which are "believed to work precisely because every trace of subjective intention had been emptied from it, leaving only an aching vacancy into which the mind of the subject would not be able to help project itself" (13), things continue to exert their thingness upon us even despite our awareness - "the things we think we do to things may turn out to be things that things do with us" (5) and with our cognition. On the other hand, because a thinking thing is "a thing apt to embody thought" (1), they can also be understood as meta-cognitive units, which not only self-reflexively (re)turn our attention to thinking - "things come into visibility when the thought of them ruptures or ebbs" (1), but also mediate such 
processes of self-knowledge - "thinking can only lay hold of itself in the form of a thing" (1). Once again, things and human beings are seen as mutually co-dependent and co-constitutive, half-agents and half to-be-known, eliciting our attention only in so far as they are inaccessible - "the things which are of most interest to us are those that exceed or fall beneath our power of thinking them, this may be because they are all incipient figuring of thought's desire to encounter in things the objects of its own thinking" (32).

It is the accumulation of these interobjective relations of understanding that, in Bruno Latour's configuration of a "sociology of associations" (Reassembling 9), aggregates a social world from which "people and things cannot be disaggregated" (Brown, Other Things 6). As theatre actors, they are always and already acting together, overtaking and other-taking each others' roles, actions, and even reasons for action. (Latour 45-46) The actor-networks thus constituted redefine societies as "bundles of composite entities" (218), whose conscious and unconscious interdetermined actions "should rather be felt as a node, a knot, and a conglomerate of many surprising sets of agencies that have to be slowly disentangled" (44). Denouncing the idea of a pre-existent "social stuff" (43) - from which human agents singularly emerge as social beings, capable of social cognition and behaviour, Latour reconstructs the social and the society as a result of constantly fluctuating waves of "re-associations and reassembling" (7) between essentially non-social entities (8), human or nonhuman -

ANT states that if we wish to be a bit more realistic about social ties than «reasonable» sociologists, then we have to accept that the continuity of any course of action will rarely consist of human-to-human connections (for which the basic social skills would be enough anyway) or of object-object connections, but will probably zigzag from one to the other (75).

From this perspective, the distribution of agency among beings and things is fundamentally reconsidered in terms of an intermediary/mediator binary. The former - while still preserving an ability to become mediators, are inert, $a$ - or presocial means of "transport[ing] meaning or force without transformation: defining its inputs is enough to define its outputs" (39). The latter are full-blown social agents, which not only foster the social - attracting other mediators, causing intersubjective 
and interobjective "relations of such a sort that they make others do unexpected things" (106), and creating networks that "render the movement of the social visible" (128), but also leave the traces of those associations -

mediators transform, translate, distort, and modify the meaning or the elements they are supposed to carry. (...) No matter how simple a mediator may look, it may become complex; it may lead in multiple directions which will modify all the contradictory accounts attributed to its role. (...) A properly functioning computer could be taken as a good case of a complicated intermediary (...) But if it breaks down, a computer may turn into a horrendously complex mediator (39).

In this way, the social world is "a world made of concatenations of mediators where each point can be said to fully act” (59). Retracing the ties back to Brown and Connor, it becomes possible to think about the sociology of associations as a record of "the movements of things in and out of their thinghood" (Connor 5 ).

The common denominator of these three theoretical approaches resides in their (re)discovering of things in the midst of (social) cognition and of society, respectively. As in the case of the commonality of sentience, the social becomes a binding force that transcends the limits of human cognition. While thinking is "properly nothing and nowhere," being able to only "lay hold of itself in the form of a thing" (Connor 1), the social "is nowhere in particular as a thing among other things but may circulate everywhere as a movement connecting non-social things" (Latour 107). Intrinsically mediating, interpreting, and obscuring, thinking becomes itself a mediator, while objects come in as its facilitators, extending (and, at times, exceeding) human agency. In this sense, the following section will explore how objects are seen as capable to encode, store, and narrativize memory in ways that create interesting interobjective relations and, at the same time, bridge intersubjective understanding across spatial or temporal boundaries.

\section{Retelling the stories of (non)human others}

Before turning to Colum McCann's novel Let the Great World Spin (2009), it is important to notice his personal contribution to a twist to the trope of putting oneself in the other's shoes. During a memorial lecture on "Literature, Empathy, and the Perils 
of Appropriation" at Bowdoin College, ${ }^{8}$ the Irish-American author intuitively de- and re-constructs the fundamental mechanisms of empathetic understanding. He emphasizes how contemporary social contexts - in particular, social media and technological advents, have reduced both narrative imagination and folk psychological narratives to insufficient and inefficient means of intersubjective understanding-

we like to think we are binding our imaginations together, but so much of the time, it seems to me, we're coming indoors, closing the curtains, locking down the GPS systems on our imaginations. (...) It seems that our stories have been handcuffed somehow, (...) that our empathetic possibility is somehow being walled off (oo:20:45-00:22:29).

The lack that McCann recognizes is- on the one hand, in our unwillingness to listen to others' stories -

we are telling our stories, we know this. We're telling them on our phones, in our photos, on our Facebook accounts, but the truth of the matter is that we can't really tell a proper story if we're not being properly listened to. And, if we want to be listened to, we have to become listeners as well, (...) we have to be involved and fully involved in the story of others (oo:23:00-29; emphasis added),

and - on the other hand, in our neglecting, even as involved listeners, of our crucial responsibility to further tell and retell the others' story, to construct a secondary narrative about and for them. Thus, putting oneself into the shoes of the other is no longer interpreted as the primary means of establishing intersubjective connections, but rather their desired outcome -

in these horrible, tumultuous, and terribly divided times, (...) to have our stories properly told, [we must] try to step into the shoes of others. It's my belief that we have to expand our sense of what the world actually is. If you tell my story, I will tell yours. If you make an attempt to understand me, I will make an attempt to understand you (oo:32:48-33:26).

Because the struggle for initiating associations with others is - in the spirit of Bruno Latour, partially mediated and overtaken by other (technological) agents, the problem

${ }^{8}$ The following excerpts are from the YouTube transcription. 
of empathy shifts to our means of preserving and subsequent handling of the intersubjective relations we are (made to) engaged in. In fact, it is a question of remaining in another's shoes, of ethically appropriating his/her experience through story-sharing (oo:32:15-45) and, thus, of expanding our understanding of the world, the other, and the self. Furthermore, it is also a means of opening up towards alterity through returning the invitation for a reciprocal empathetic exercise.

Returning to Groes' and Meretoja's perspectives on the status of empathy and cognition in today's world, it is interesting to notice that McCann also explicitly identifies them as causes. From the use of phrases such as "the GPS systems of our imagination" to discussions on the relation between social media and solipsism, issues of discrimination or the dangers of cultural appropriation, he reinforces the plea for perspective-taking and dialogicality -

in these dark times, in the globalized world of mutual dependencies - in the current age of terror, displacement, global warming, and the rise of populist, nationalist, and right-wing extremist movements - the need to perceive the world from a plurality of perspectives is as acute as ever (Meretoja 304; emphasis added).

The first perspective taken by McCann's polyphonous novel is that of Philippe Petit and his historical tightrope walk across the Twin Towers on August 7, 1974. Several different perspectives are adopted in succession, following the lives of those that (could have) witnessed or have been influenced by the performance. Revolving around loss, trauma - and the pre-trauma of an unconscious anticipation of the terrorist attack -, and death, the fictional minds (Palmer) and memories meet, overlap, and diverge. In the same morning of the walk, a support group of mothers who had lost their sons in the Vietnam War try their chance at therapeutic storytelling, while Corrigan, an Irish monk, dies in a car accident together with a Bronx prostitute, one of the friends he took care of and helped. Multiple ripple-effects ensue, including the wife of the other driver involved in the accident falling in love with the mourning brother of the monk and - presumably at the same time -, a hacker from Florida asking a New Yorker on a date after a 10-minute payphone call through which he tried to gain a quasi-direct account of the funambulist's spectacle. Numerous other voiced and nonvoiced characters are entangled in these complex webs that gradually defamiliarize our 
understanding of empathy, social cognition, and memory, and contribute to its stretching towards nonhuman others as well.

In addition to being a conscious exercise in storytelling, perspective-taking, and empathy, the novel is also an attempt to test their tentative limits. Constructing a "narratology of otherness" that "renders «otherness» a narrative as much as a political designation" (Gilligan 116), McCann often subordinates the personal to the interpersonal and - correspondingly, the processes of self-understanding to those of intersubjective understanding. In this way, storytelling is no longer a means of identity construction, but becomes a vulnerable availability towards otherness, including both the encountered and to-be-understood (non)human, and the listeners. For example, the third chapter of the novel tells the story of Claire Soderberg - and, through her narrativized memories, of her son, Joshua - while also setting up their clash with other stories of the support group's member and of the tightrope walking performance. Claire's social background - a Yale graduate with a Mathematics degree, the wife of a Jewish judge and living on the Upper East Side - comes in sharp contrast with that of the other moms. It is the war - and "the disgusting proximity of it" (87), death - as "the greatest democracy of them all" (107), and memory that manage to bring (and keep) them together. Arranging regular meetings, the group visits each other's houses, where they engage with the remainders of their sons - their photographs, their rooms, the announcement of their death. However, the storytelling rituals become so detached from self-oriented pursuits that - counterintuitively, they seem to fail as a therapeutic method.

A possible reason concerns the construction of memory, which, at this point in the novel, still follows a competitive model (Rothberg 5), determining the failure of empathy and intersubjective understanding. To Claire, the accounts of the tightrope walking event appear as intrusive narratives, "coming in like a hack on her morning (...) on her [and Joshua's] code (...) munching away what should have been" (113). However, if the keywords are backtracked, it can be argued that the mother's conclusion hides a deeper level of intersubjectivity. Code writing had been previously put in relation to Joshua's military position as a software developer with a specific project on a program for counting war casualties. Hacking was - firstly, used as a reference to the programmers' means of socializing - "most of the intrusions were from members of his own squad (...) and it was just a thing to pass the time, to hack another man's code, to test his strength, find his vulnerability. Harmless, really, 
Joshua said" (99-100), and - secondly, it represented Joshua's first-hand war battles against harmful and unsympathetic cybernetic attacks9- "The small blipping cursor ate away what he'd been doing. His code got munched" (100). A similar ambivalence describes Claire's reactions to the macro-narrative of the funambulist as well. Even though it is violently superimposed and it blocks the channel that was primarily opened to contain her story of vulnerability, the mother insists in entering the dialogue he had initiated in order to make sense of his personal narrative and intentions. Despite her efforts, her last interpretation maintains a covert "competition of victims" (Rothberg 2) and thus fails empathically. It 'attacks' back through a projection of her own story -

He was up there out of a sort of loneliness. What his mind was, what his body was: a sort of loneliness. With no thought at all for death. (...) How dare he do that with his own body? Throwing his life in everyone's face? Making her own son's so cheap? (1123).

As follows, the competitive model of memory would gradually be deconstructed, but an important step is the extension of empathy to nonhuman others. Because all micronarratives of the novel are similar attempts at intersubjectivity across boundaries of space, time, or death, human social cognition is removed from its usual contexts of embodied and enactive information and thus challenged beyond its common capacities. Consequently, the number of epistemological gaps of intersubjective understanding increase. In this sense, it will be argued that one of the solutions proposed by the novel consists in a complementary cognitive exercise in extending the scope of perspective-taking and perspective-awareness towards nonhuman others in order to fill in the gaps of intersubjectivity through an accumulation of objects and interobjective relations.

In this way, closely approximating Steven Connor's thinking things, objects often "draw, drain and detain" (4) human cognition. On the one hand, they claim their capacities for story-telling and story-storing - for instance, they freely circulate through different chapters, fictional minds, and actor-networks as substitutes for character's narrative identities, such as neon-yellow bikini tops, swimsuits, stilettos,

\footnotetext{
9 The anthropomorphization of the cursor and the code are representative for both Joshua's interobjective relations with technology and the attacker's reliance on the potential agency of the software against its writer.
} 
fur coats, and a parasol for a group of Bronx prostitutes (24-6, 29, 53, 69, 207, 217, 266), or the Bible and a hospital box of possessions for Corrigan $(22,44,69,136-8)^{10}$. On the other hand, they can also function as minimal cognitive units, facilitating memory processes. In this sense, many objects - or even their pressing absence become repositories of the past. Ciaran's missing ear-lobe is, to him, a memento of Irish political violence and bombing (26) and a storyteller in Dublin - "the tip of my ear left behind on the street" (21). Similarly, they can also be associated with the cognitive processes of intersubjectivity and interobjectivity. As Joshua's code writing and hacking, it is possible to retrieve traces of the associations between empathy and apricots. First mentioned after a social encounter - "it is the first time in years that she's opened herself to a stranger. It's as if she has bitten into the skin of an apricot" (330), the mental stimuli triggered by the fruit return at the very end of the novel. Forced into more radical acts of intersubjective understanding both a dying close person and death itself, Jaslyn "thinks again of an apricot - she does not know why, but that's what she thinks, the skin of it, the savour, the sweetness" (349). Even though the association is not explicitly rationalized, its mediation is sufficient. The conclusion comes almost as an epiphany - "The world spins. We stumble on. It is enough" (349).

Beyond interobjective relations as supplements to intersubjective ones, things can also orchestrate otherwise impossible intersubjective (re)connections. In this sense, they must engage in a double manifestation of their thingness. A telling example returns to the story of Claire, Joshua, and the Hairy Fridge. After her son left for Vietnam, Claire turned to electricity and electronic devices in order to artificially recreate an interconnection with her son -

It was as if she could travel through the electricity to see him. She could look at any electronic thing - television, radio, Solomon's shaver - and could find herself there, journeying along the raw voltage. Most of all it was the fridge. (...) No sound, just a soft plop of the rubber- edged opening, and then a rush of cold over her body, and she could

\footnotetext{
${ }^{10}$ Some of the most representative examples concern Tillie's choice for the parasol during her transition to the streets of Bronx, "I wasn't a parasol girl down on Forty-ninth and Lex. The parasol was a thing I started in the Bronx" (217), the remainders of Jazzlyn and Corrigan after their car accident, which are also capable of substituting for the entire event - "the only thing of hers they found later in the van was a yellow stiletto, with a Bible sitting canted right beside it, having fallen out of the glove compartment, one on top of the other and both of them littered with glass" (69), and Lara's relation with the hospital box of Corrigan's possession as their only social encounter, "the cardboard box sat in the passenger seat beside me. An unknown man's life" (136).
} 
gaze past the wires, the cathodes, the transistors, the hand- set switches, through the ether, and she could see him (86-7).

Interestingly, the mediated intersubjective encounter does not elude the possibility of compassion and empathy -"all of a sudden she was in the very same room, right beside him, she could reach out and lay her hand on his forearm, console him" (87). Moreover, after the death of Joshua - and his materialization into code, "written into his own numbers" (89), Claire begins to anthropomorphize his electronic substitute, reinforcing her previous claim that "so much more than photographs [keep the dead alive]" (79) - "she put Joshua's photo front and centre. She leaned against it and talked to him" (90). A consequence to imposing a human mould on the object, Claire also assumes that its interobjective relations should be multiplied -

the fridge collected things that he might have liked. Simple things. She cut them out and pasted them on. Computer articles. Photos of circuit boards. A picture of a new building at PARC. A newspaper article about a graphics hack. The menu from Ray's Famous. An ad from The Village Voice. It struck her that the fridge was beginning to look hairy. The phrase almost made her smile. My hairy fridge (90).

It may also be important to notice that Claire is consciously considering the extents of the agency of technological software and hardware - "how was it, she wondered, that machines could count the dead better than humans? (...) How did a series of tubes and wires know the difference between the living and the dead" (87). The tension is immediately resolved through Joshua's belief in the possibility of writing a program that "created a space for [the death] so that they became a sort of alive" (88).

Beyond his experimentation with means of constructing intersubjectivity, interobjectivity, and (non)human agency, McCann also experiments with the limits of memory, remembering, and forgetting. As a complement to the dialogic network of associations between human and nonhuman actors alike, the mechanisms of memory are to be equally flexible and recognizing of otherness. Being once again cognitively challenging, the model proposed by McCann mirrors Michael Rothberg's theory of multidirectional memory. On the one hand, it reinforces a similar spirit of (non)human intersubjective dialogue - "memory's multidirectionality encourages us to think of the public sphere as a malleable discursive space in which groups do not simply articulate established positions but actually come into being through their 
dialogical interactions with others" (Rothberg 5). On the other hand, through its "anachronistic quality - its bringing together of now and then, here and there" (5), it resonates with McCann's intentions of fictionalizing a historical event in order to create an alternative and oblique response to the terrorist attacks of 9/11. Despite the historical event's intradiegetic absence, its immanence haunts as a time-travelling spectre - "the cultural and psychological impact of $9 / 11$ is so profound and long-lasting that it has traveled backwards through time to penetrate the past, changing how we apprehend and remember the events long before 9/11 actually happened" (Liao 123). In the context of things' agency, it is also an account of how their potential for interconnectedness easily transcends the limitations of humans.

From this perspective, the last chapter's temporal leap, from 1974 to a seemingly usual day in a New York airport in October, 2006, is significant. A thinking thing accompanies the emergence of the last of the fictional minds composing the novel. It is a photograph of the tightrope walk. Even though Jaslyn was rather a nonparticipant to the event, being too young to remember it, she has the more important role of being the owner of its remainder. "One of her favourite possessions" (326), the photograph is part of her memory and self-identity because it was taken on the day of her biological mother's death. At the same time, it is part of her suitcase's identity as well- "[it] would feel wrong without it, as if it were missing a latch. When she travels she always tucks the photo in tissue paper along with the other mementoes: a set of pearls, a lock of her sister's hair" (326).

Printed in the novel (237), the photograph is also materially accessible to the readers - the other historical non-participants. Directly faced with the question of object's agency, we are to compare the photographic narrative with the narrator's attempt to "language us into vision" (McCann, Letters, e-book) -

a man high in the air while a plane disappears, it seems, into the edge of the building. One small scrap of history meeting a larger one. As if the walking man were somehow anticipating what would come later. The intrusion of time and history. The collision point of stories. We wait for the explosion but it never occurs. The plane passes, the tightrope walker gets to the end of the wire. Things don't fall apart (The Great World 326). 
In this way, the photograph exerts its agency not only towards all the other characters of the book - (re)binding and holding their micro-histories together along the macronarrative of the tightrope walker in a Latourian network of associations, but also towards us. As Jaslyn, we (in)voluntarily engage in the mental $d e$ - and re-construction of the Twin Towers, which renders the photograph not only a relic of memory, but also a foreshadower of the spectrally haunting terrorist act. It is the subsequent realisation that the human mind cannot help the projection of its own memories of trauma on things, while the thing itself effortlessly tells the stories of multiple and multidirectional memories. Moreover, it is not reduced to a mere informant, but remains a mediator "still capable of myth in the face of all other evidence" (326), that forces us into acknowledging its agency. Despite the apparent coagulation around acts of storytelling and memory narrativization, the apeirogonic story-world of the novel is not bound together by them - the "«social» is not some glue (...) it is what is glued together by many other types of connectors" (Latour 5 ). A connector that resisted time, the photograph of Philippe Petit is only a small part of the "ontological glue" (326) that "holds the man so high in the air" (326), far beyond common human capacities and at the same time, far beyond the gluing capacities of human narrative accounts of the performance.

Even if only at the textual level of the "material unconscious" (Brown, Other Things 9) - on which various arts "register transformations of the material world that they do not necessarily represent or intentionally express" (9), the things in McCann's novel become full-blown actors. Not only nodes of various actor-networks, but also cognitive appendages that expand human agency beyond its mental, biological, or empathetic limitations, things are recognized and encountered as autonomous others. Responding to their (re)claimed right to direct empathetic understanding, both characters and readers find that the 'shoes' of things fit as well and that their inner experience can be even more world-expanding.

Accepting that there is neither a cognitive commonality, nor a pre-existing social force that can justify our drawing the boundaries of communities in accordance to human agents, this paper attempted to respond to Bruno Latour's claim that "our political future resides in the task of deciding what binds us all together" (Reassembling 8). While answers ranged from "a shared sentiency" (Meretoja 125) to bundles of mediators and connectors that create a society and a sociology of associations (Latour), or from McCann's idea of a collaborative imagination to the 
potentially infinite entities that constitute an "ontological glue" (326), it becomes apparent that the contribution of nonhuman others is essential. They are agents capable of both other-taking (Latour) our actions and - most importantly, of expanding our cognitive capacities. They show that the human subject is neither the sole master of his cognition, nor the autonomous agent of his actions and interactions. Causes and consequences of the changing contemporary world, these perspectives suggest not only that human character is changing, but also that it is necessary for us to recognize the existence of an equally complex nonhuman character.

\section{References:}

Brown, Bill. "Thing Theory," Critical Inquiry, 28 (1), 2001: 1-22.

---. Other Things. University of Chicago Press, 2016.

Cohen, Samuel. After the End of History: American Fiction in the 1990s. University of Iowa Press, 2009.

Connor, Steven. "Thinking Things." An extended version of a plenary lecture at the $9^{\text {th }}$ annual conference of the European Society for the Study of English (ESSE), August 25, 2008, Aarhus, Denmark and the Textual Practice lecture, October 14, 2009, University of Sussex. Published at stevenconnor.com/thinkingthings/thinkingthings.pdf.

Gallagher, Shaun. "Narrative Competence and the Massive Hermeneutical Background." Education, Dialogue and Hermeneutics. Ed. Paul Fairfield. Continuum International Publishing Group, 2011: 21-38.

Gilligan, Ruth. "Towards a «Narratology of Otherness»: Colum McCann, Ireland, and a New Transcultural Approach.” Studies in the Novel. 48.1 (2016): 107-125, DOI: 10.1353/sdn.2016.0005.

Groes, Sebastian. Memory in the Twenty-First Century: New Critical Perspectives from the Arts, Humanities, and Sciences. Palgrave MacMillan, 2016.

Grusin, Richard. The Nonhuman Turn. University of Minnesota Press, 2015.

Herman, David. The Emergence of Mind: Representations of Consciousness in Narrative Discourse in English. University of Nebraska Press, 2011.

---. "1880-1945: Re-minding Modernism." The Emergence of Mind: Representations of Consciousness in Narrative Discourse in English. Ed. David Herman. University of Nebraska Press, 2011: 243-72. 
Hutto, Daniel D. Folk Psychological Narratives. The Sociocultural Basis of Understanding Reasons. The MIT Press, 2008.

Latour, Bruno. Reassembling the Social: An Introduction to Actor-Network-Theory. Oxford University Press, 2005.

---. We Have Never Been Modern. Translated by Catherine Porter, Harvard University Press, 1993.

Liao, Pei-chen. Post-9/11 Historical Fiction and Alternate History Fiction: Transnational and Multidirectional Memory. Palgrave Macmillan, 2020.

McCann, Colum. "Literature, Empathy and The Perils of Appropriation," Kenneth V. Santagata Memorial Lecture, October 4, 2018, Bowdoin College. YouTube, uploaded by Bowdoin College, October 5, 2018: www.youtube.com/watch?v=Q96QHdfZZsE.

---. Let the Great World Spin. Random House, 2009.

---. Letters to a Young Writer: Some Practical and Philosophical Advice. E-book, Random House, 2017.

Meretoja, Hanna. The Ethics of Storytelling: Narrative Hermeneutics, History, and the Possible. Oxford University Press, 2018.

Moses, Louis J., and Jodie A. Baird. "Metacognition.” The MIT Encyclopedia of the Cognitive Sciences. Ed. Robert A. Wilson and Frank C. Keil. The MIT Press, 1999: 533-35.

Palmer, Alan. Fictional Minds. University of Nebraska Press, 2004.

Pinker, Steven. The Blank Slate: The Modern Denial of Human Nature. Viking, 2002.

Rothberg, Michael. Multidirectional Memory: Remembering the Holocaust in the Age of Decolonization. Stanford University Press, 2009.

Shaviro, Steven. “Consequences of Panpsychism.” The Nonhuman Turn. Ed. Richard Grusin. University of Minnesota Press, 2015: 19-45. 